\title{
Synthesis of a MUC1 Mucin Cyclic Dimer Peptide and Its Antibody Binding Properties as Revealed by STD-NMR
}

\author{
Cheng Her \& Thao Yang* \\ Department of Chemistry, University of Wisconsin - Eau Claire, Eau Claire, WI \\ Student: herxx373@umn.edu \\ Mentor: yangt@uwec.edu
}

\begin{abstract}
In a previous study we showed that the shortened MUC1 mucin peptide GVTSAPD could bind monoclonal antibody (mAb). We proceeded on to make a cyclic peptide of the same sequence to see if it would be more effective in binding antibody. We were able to synthesize and isolate two different cyclic mucin peptides: 1) a monomer cyclic peptide with sequence GVTSAPD which we did not study due to difficulties in achieving homogeneity, and 2) a dimer cyclic peptide with sequence GVTSAPDGVTSAPD that was successfully isolated and studied. We describe here the results of the dimer cyclic peptide-antibody interactions obtained by Saturation Transfer Difference NMR (STDNMR). The results indicated that the protons of all residues experienced STD effects, notably being more pronounced at Pro, Val, Ala and Asp compared to the linear peptide GVTSAPD. The Pro residue exhibited STD peaks for all its side chain protons with stronger intensity at $\mathrm{ProH} \gamma$ while Ala, Val and Thr are localized to methyl groups.
\end{abstract}

\section{KEYWORDS}

Mucl Antibody Recognition Epitope, STD NMR, Mucin Peptide-antibody Interactions, Cyclodimer Peptide.

\section{INTRODUCTION}

The mucin protein, encoded by the MUC1 gene, is an epithelial transmembrane glycoprotein of which the extracellular domain exhibits a repeating 20 amino acid sequence (GVTSAPDTRPAPGSTAPPAH) known as the Tandem Repeat Domain (TRD). ${ }^{1-3}$ The TRD contains five O-linked glycosylation sites (underlined) to which the attached carbohydrates aid in carrying out the normal cellular functions of MUC1 mucin, which includes binding of pathogens as a protective system, cell signaling, and lubrication/hydration of the epithelial surfaces. ${ }^{1,2}$ Studies have shown that the MUC1 mucin amino acid sequence of cancer and normal cells of the epithelia are identical. ${ }^{2}$ Human adenocarcinomas exhibit overexpression of MUC1 mucin of truncated oligosaccharide structures at the TRD region which makes it distinguishable from normal epithelial cells. ${ }^{1-5}$ These discoveries are significant to the extent that reduced glycosylation of MUC1 mucin allows access of the TRD to the immune system producing low level immunity. ${ }^{6,7}$ Expression of MUC1 mucin and its glycosylation content of the TRD have been studied extensively and suggested to hold high therapeutic potentials against cancers. ${ }^{8,9}$

The structural differences between the two forms of MUC1 mucins have generated interest and led effort in utilizing MUC1 mucin in immunotherapy of cancer. ${ }^{10,11}$ It has been reported that antibody responses specific for MUC1 mucin have been detected in patients of breast, pancreatic and ovarian cancers, and other studies have discovered a binding site of these antibodies to the MUC1 mucin to be at the sequence PDTRP at the TRD. ${ }^{2-4}$ In a previous study we have determined that the linear sequence GVTSAPD is also capable of binding to mAb (6A4) from mouse with significant interactions at the proline residue. ${ }^{12,13}$ This demonstrates that the $\mathrm{mAb}$ raised against specific antigen epitope can interact with peptides with similar structure to its binding interface, and that 
absolute specificity is not a requirement, which may offer, as a general strategy, more room for improvement in the design of variety of antigenic agents to induce the same kind but more effective immunity in the area of MUC1 mucin based cancer immunotherapy. In an attempt to develop a mucin peptide epitope that can interact effectively with MUC1 mAb that may potentially be capable of inducing sufficient immunity without being compromised by cellular enzymatic reactions, we proposed to design cyclic peptides and other non-natural amino acid peptide derivatives based on the known antigenic sequence of the MUC1 mucin. Cyclic peptides based on known epitope sequence may give increased peptide-antibody affinity, which may afford them as additional antigenic agents. Herein we report the synthesis and preliminary results of the antibody binding properties of a cyclic dimer peptide, which has its sequence repeated twice based on the sequence GVTSAPD.

\section{ABBREVIATIONS}

DCM, dichloromethane; DIPEA, diisopropylethylamine; DMF, dimethylformamide; Fmoc, $\mathrm{N}$ - $\alpha$-9-fluorenylmethoxycarbonyl; HBTU, O-(Benzotriazol-1-yl)-N,N,N',N'-tetramethyluronium hexafluorophosphate; HOBt, N-hydroxybenzotriazole; ODmab, 4\{N-[1-(4,4-Dimethyl-2,6dioxo-cyclohexylidene)-3-methylbutyl]-amino\}benzyloxy; PyBOP, benzotriazole-1-yl-oxy-trispyrrolidino-phosphonium hexafluorophosphate; TIC, total ion current; Wang resin, $p$-alkoxybenzyl alcohol-linked Wang resin; $\mathrm{u}, \mathrm{m} / \mathrm{z}$ unit.

\section{EXPERIMENTAL PROCEDURES}

SPPS of Cyclic Mucin Peptide.

The peptide was synthesized via standard Fmoc-chemistry by Solid Phase Peptide Synthesis (SPPS). ${ }^{14}$ For specific details on building the peptide chain and cleavage, see references 12 and $13 .{ }^{12,13}$ The pre-loaded resin used was Fmoc-Asp (Wang resin LL)-ODmab (Novabiochem). After the entire sequence has been synthesized, the ODmab group protecting the $\alpha$-carboxyl group at the C-terminus of the peptide was removed with $2 \%$ hydrazine $(\mathrm{v} / \mathrm{v})$ in DMF and then vacuum dried for cyclization. The cyclization reagents consisted of a mixture of $4 \mathrm{x}$ excess of resin of PyBOP, HOBt and 2x excess of DIPEA. The head-to-tail cyclization strategy was carried out for $24 \mathrm{hrs}$. Scheme 1 summarizes the general strategy for synthesis of the cyclic mucin peptide. ${ }^{15,16}$

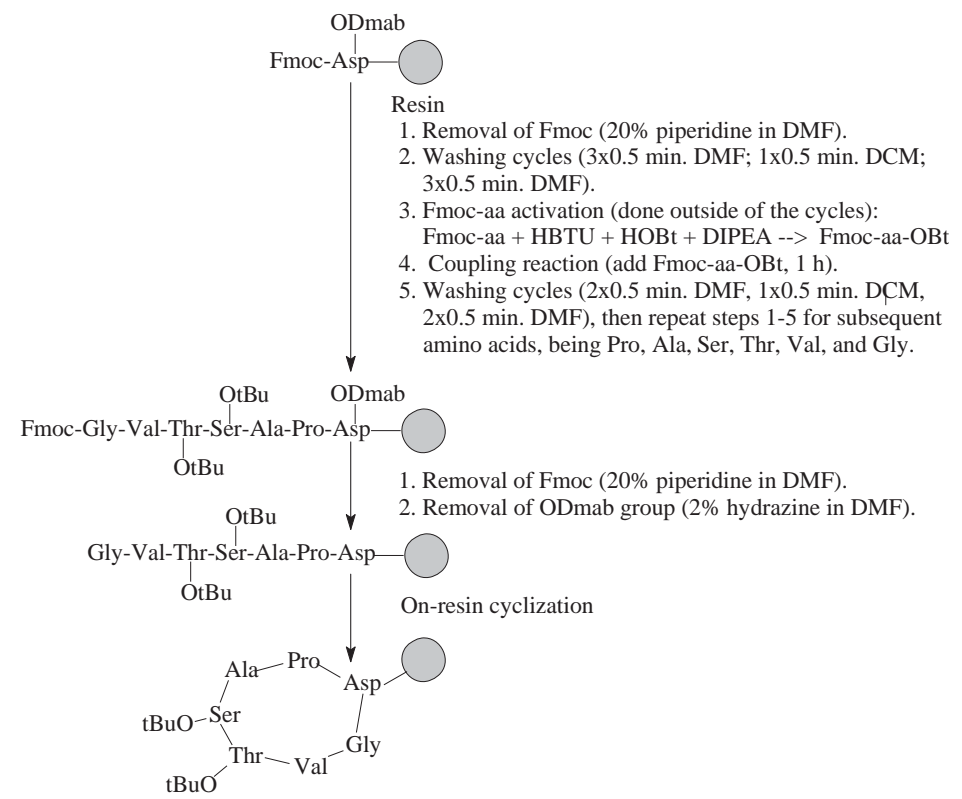

Scheme 1. General scheme for the strategy of cyclic peptide synthesis. The Asp side chain is linked to the resin; the ODmab group is on the a-CO2-group of Fmoc-Asp-resin 


\section{HPLC Purification of Peptides.}

Peptide was purified using a Varian Prostar HPLC. ${ }^{12,13}$ The method used a reverse phase preparative $\mathrm{C}_{18}$ column (10x250 mm, $10 \mu \mathrm{m}$, Grace Vydac) with acetonitrile (ACN) as the organic mobile phase and monitored at $220 \mathrm{~nm}$. The flow rate was set at $2 \mathrm{~mL} / \mathrm{min}$ with a gradual increase in ACN from $0-35 \%$ at the $30 \mathrm{~min}$. mark. Fractions were collected manually and freeze-dried for storage and subsequent NMR experiments. The buffers used in the HPLC were $1 \%$ ACN, $0.1 \%$ HOAc (acetic acid), $98.9 \%$ water (buffer A), and $1 \%$ water, $0.1 \%$ HOAc, $98.9 \%$ ACN (buffer B).

\section{LC-MS Analysis.}

The freeze-dried solid peptide sample was analyzed for presence of the desire product with an Agilent Mass Spectrometer (Agilent Technologies Time-of-Flight LC/MS 6210). The buffers used in the LC-MS analysis were the same as in HPLC. The conditions used in the LC-MS were: $0.5 \mathrm{~mL} /$ min flow rate, $5-100 \% \mathrm{~B}$ in 20 minute buffer gradient, $20 \mathrm{~min}$. acquisition time followed by a $4 \mathrm{~min}$. post run, $\mathrm{C}_{18}$ column $\left(4.6 \mathrm{x} 150 \mathrm{~mm}, 3.5 \mu \mathrm{m}, \mathrm{ZORBAX}\right.$ Extend- $\left.\mathrm{C}_{18}\right)$ and ESI positive mode. ${ }^{12,13}$

\section{NMR Experiments.}

All NMR experiments were performed using a $400 \mathrm{MHz}$ Bruker Avance Spectrometer. Generally, peptide samples were at 3-5 mM, in $20 \mathrm{mM}$ phosphate buffer, $5 \mathrm{mM} \mathrm{NaCl}$, pH 5, 90\% $\mathrm{H}_{2} \mathrm{O}$, $10 \% \mathrm{D}_{2} \mathrm{O}$, at $7^{\circ} \mathrm{C}$. The $2 \mathrm{D}$ NMR (TOCSY and ROESY, Bruker TopSpin software v. 2.0.5) data were collected for proton assignments. The TOCSY data give the spin system of each amino acid residue; thus, ${ }^{1} \mathrm{H}-{ }^{1} \mathrm{H}$ connectivity through bond within each amino acid residue. The ROESY data allow for ${ }^{1} \mathrm{H}-{ }^{1} \mathrm{H}$ connectivity between the sequential amino acids as well as through space long range interactions between two ${ }^{1} \mathrm{H}^{\prime}$ s that may be close spatially within $5 \AA \AA^{17,18}$ Suppression of $\mathrm{H}_{2} \mathrm{O}$ signal in the 2D NMR spectra was accomplished by the 3-9-19 WATERGATE pulse sequence with gradients applied at each cycle of the 2D TOCSY or ROESY pulse sequence. ${ }^{19}$

The STD NMR technique was used to study the binding interactions of peptide ligand with antibody. ${ }^{13,20,21}$ Mixture samples of $0.01 \mathrm{mM}$ of mouse Mucl specific monoclonal antibody IgG1 (6A4 clone, $\mathrm{Mr}_{\mathrm{r}} 122 \mathrm{kDa}$, Genway Biotech) with $1 \mathrm{mM}$ of peptide ligand were used (peptide:antibody ratio $=100: 1$ ). The STD NMR data were collected with peptide-antibody mixtures made up in $20 \mathrm{mM}$ phosphate buffer, $5 \mathrm{mM} \mathrm{NaCl}, \mathrm{pH} 7,100 \% \mathrm{D}_{2} \mathrm{O}$, at $7^{\circ} \mathrm{C}$ with presence of considerable $\mathrm{HDO}$ signal. At $\mathrm{pH} 7$, the aliphatic ${ }^{1} \mathrm{H}$ NMR resonances do not deviate unambiguously from those at $\mathrm{pH} 5$. In the STD NMR technique, two NMR spectra were collected; one with the on-resonance frequency set at $-2 \mathrm{ppm}$ where there are no peptide ${ }^{1} \mathrm{H}$ signals but antibody ${ }^{1} \mathrm{H}$ signals are present, and the other with the off-resonance frequency set at $+40 \mathrm{ppm}$ where there are no ${ }^{1} \mathrm{H}$ signals from either ligand or antibody. The saturation time was $2 \mathrm{~s}$. The on-resonance spectrum intensity (ISAT) is subtracted from the off-resonance spectrum intensity $\left(\mathrm{I}_{0}\right)$ to obtain the STD NMR spectrum (ISTD $=\mathrm{I}_{0}-\mathrm{I}_{\mathrm{SAT}}$ ); the amplification factor (ASTD) is calculated by the equation: ASTD $=\left(I_{S T D} / \mathrm{I}_{0}\right) \mathrm{x}[\mathrm{L}] \mathrm{t} /[\mathrm{P}]$, where $[\mathrm{L}] \mathrm{t}$ is the total peptide concentration and $[\mathrm{P}]$ is the antibody concentration. If there is any proton on the ligand that directly binds the antibody, it will show a positive STD signal; the proton closer to the antibody will receive more saturation transfer effect and its ISTD peak intensity will be higher. ${ }^{21}$ If the peptide does not bind the antibody (e.g., no ${ }^{1} \mathrm{H}$ 's on the peptide experienced any saturation transfer effect), the resultant subtracted spectrum (STD spectrum) will have no signals (flat line). ${ }^{16,17}$ The STD NMR spectrum was used to identify which proton on which amino acid residue on the peptide has direct binding at the antibody binding interface. 


\section{RESULTS}

Synthesis.

Synthesis of the cyclic mucin peptide produced two major products of interest. The proposed reactions that led to the two peptides are illustrated on Scheme 2, where an intrachain head-to-tail reaction led to the monomer cyclic peptide (mass $627.31 \mathrm{Da}$ ), and an interchain head-to-tail reaction led to the dimer cyclic peptide (mass $1254.60 \mathrm{Da}$ ).

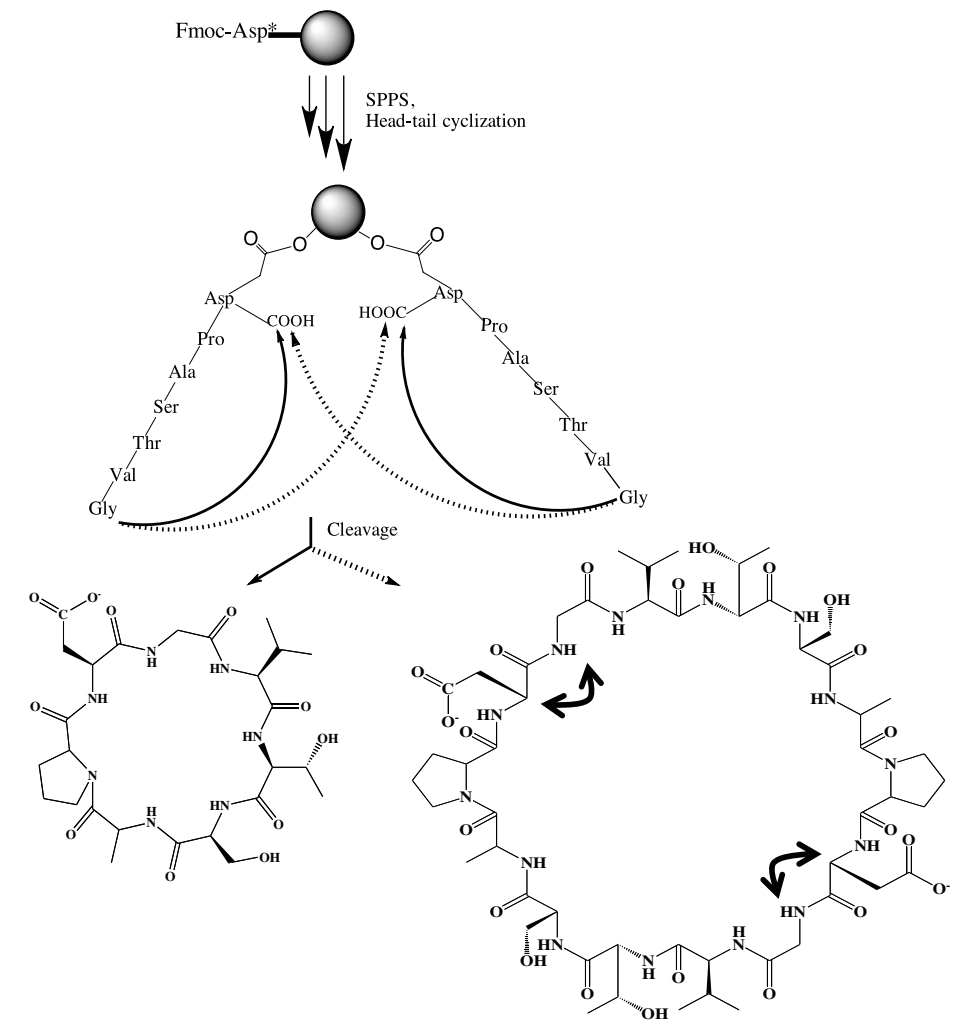

Scheme 2. Peptide cyclization mechanisms resulting in two different cyclic peptides: a cyclomonomer peptide via intrachain head-to-tail reaction (left, solid pathway, mass $627.31 \mathrm{Da}$ ) and a cyclodimer peptide via interchain head-to-tail reaction (right, dashed pathway, mass $1254.60 \mathrm{Da}$ ). " * ” signifies ODmab group on the $\alpha$ - $\mathrm{CO}_{2}$-group of Fmoc-Asp-resin; curved double headed arrows indicate NOE's that would be observed on the cyclodimer. 


\section{HPLC Analysis.}

HPLC purification following the synthesis of the mucin cyclic peptide produced three separate peaks at approximate retention times of 19.7, 23.6 and 34.0 min. Figure 1 shows the HPLC chromatogram of the crude peptide sample in which the cyclic monomer peptide and cyclic dimer peptide were isolated and purified. Subsequent LC-MS analysis of the collected pools of peaks a, b and c from HPLC (Figure 1, peaks a, $\mathbf{b}$, and $\mathbf{c}$ ) showed that these three peaks corresponded respectively to the cyclic monomer peptide of mass $628.31 \mathrm{Da}$ (peak a), the cyclic dimer peptide of mass $1255.60 \mathrm{Da}$ (peak b) and an elution peak (peak c) that contained no products of interest. There was no significant elution before the 20 min. mark as the amount of ACN being pumped through was relatively low. Most of the contaminants and unwanted side products eluted after the cyclic dimer peak at 24 min. when the amount of organic solvent being pumped through was over $30 \%$. The peaks of interests (retention times 19.7 and $23.6 \mathrm{~min}$.) were collected, freeze-dried and re-purified by HPLC a second time and their chromatograms showed a single peak with the expected retention times (data not shown) before they were used for later experiments.

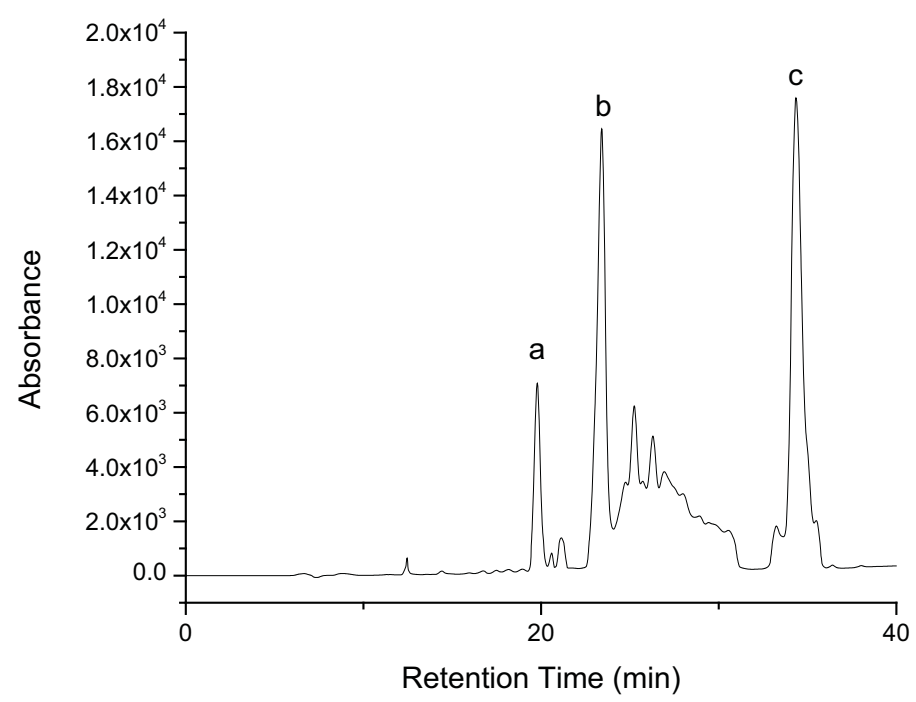

Figure 1. HPLC purification of crude peptide sample. The HPLC chromatogram was obtained from a $500 \mu \mathrm{L}$ concentrated sample injection. Acquisition time was $40 \mathrm{~min}$. with a $5 \mathrm{~min}$. post equilibrium/hold and monitored with UV light. Chromatogram was extracted from wavelength of $220 \mathrm{~nm}$; (a) peak corresponding to the cyclic peptide of interest with mass of $[\mathrm{M}+\mathrm{H}]^{+}=628.31 \mathrm{Da}$, (b) peak corresponding to the dimer cyclic peptide of interest with mass of $\left[\mathrm{M}_{\text {dimer }}+\right.$ $\mathrm{H}]^{+}=1255.60 \mathrm{Da}$, and (c) impurities found in the crude peptide sample that did not contain any products of interest. 


\section{LC-MS Analysis.}

LC-MS analysis of the crude peptide sample following synthesis showed the presence of two dominant masses in the finished product mixture. Figure $\mathbf{2}$ shows the chromatogram of the LC-MS analysis of the crude peptide (Figure 2B) and a purified dimer peptide (Figure 2A).

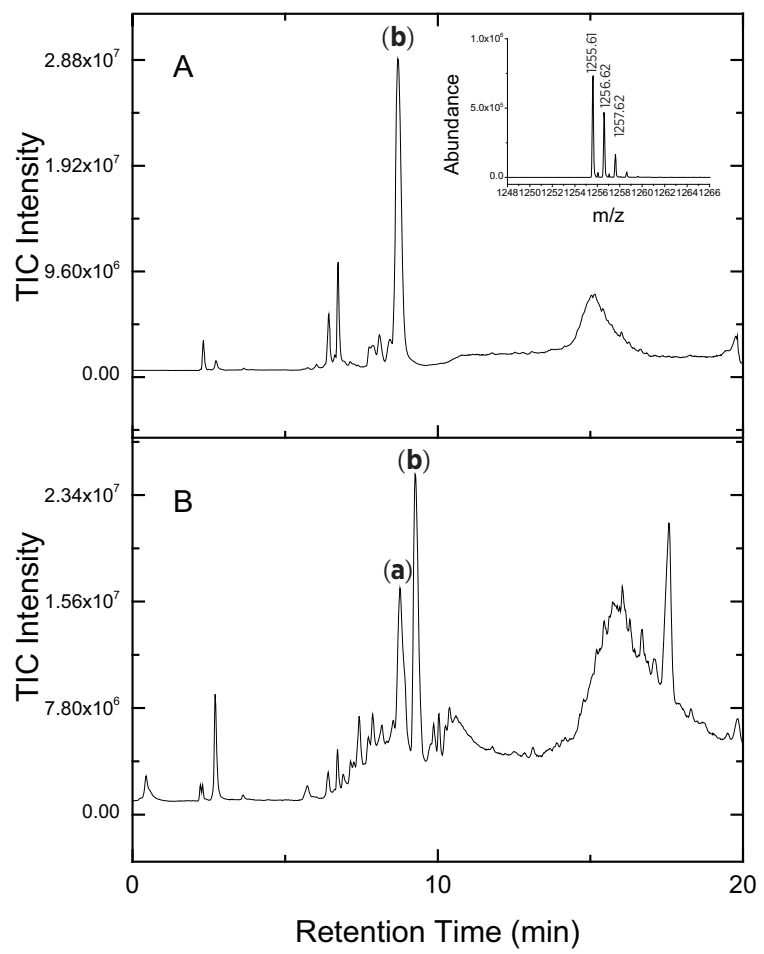

Figure 2. LC-MS chromatograms of purified (A) and crude (B) peptide samples following completion of peptide synthesis and extraction. Peaks of interest were (a) product of mass $[\mathrm{M}+\mathrm{H}]^{+}=628.31 \mathrm{Da}$ and $(\mathbf{b})$ product of mass $[\mathrm{Mdimer}+$ $\mathrm{H}]^{+}=1255.60 \mathrm{Da}$; inset on Figure 2A shows the isotopic m/z value of this singly charged ion at $1255.61 \mathrm{u}, 1256.62 \mathrm{u}$ and $1257.62 \mathrm{u}$.

Two distinct ions of $\mathrm{m} / \mathrm{z}$ values of $628.31 \mathrm{u}$ and $1255.60 \mathrm{u}$ in the TIC eluted at approximately 8.75 min. and $9.25 \mathrm{~min}$., respectively (Figure 2B). These two ions were indicative of a monomer cyclic GVTSAPD $\left(\left[\mathrm{M}+\mathrm{H}^{+}\right]_{\mathrm{calc}}=628.64 \mathrm{u}\right)$ and a dimer cyclic GVTSAPDGVTSAPD $\left(\left[\mathrm{M}_{\text {dimer }}+\mathrm{H}^{+}\right]_{\mathrm{calc}}\right.$ $=1255.29 \mathrm{u}$ ). The other peaks in the TIC did not contain any masses of interest and were accepted as contaminants or side products from the synthesis. The 1255.60 Da peptide collected from HPLC (from Figure 1, peak b) was reanalyzed by LC-MS and showed a major peak at the expected retention time of $9.25 \mathrm{~min}$. (Figure 2A). The ion at $1255.60 \mathrm{u}$ could not have been made up of an adduct of two single cyclic monomers, which would also have the same $\mathrm{m} / \mathrm{z}$ value of $1255.60 \mathrm{u}$ $\left(\left[2 \mathrm{M}_{\text {monomer }}+\mathrm{H}^{+}\right]=1255.60 \mathrm{u}\right)$, because we have collected that peak from HPLC and have repurified it by HPLC the second time, and we did not observe an equilibrium of monomer-dimer adduct formation, instead we obtained only a single peak at the expected retention time. This was true in both cases when we used both purified samples and reran the HPLC and LC-MS. If the ion at 1255.60 Da was due to a dimer adduct of two cyclic monomers, we would expect the cyclic monomer peak to be present or increasing in the reruns of HPLC and LC-MS experiments, however these were not the case. It is not entirely unexpected to obtain dimer or oligomers during peptide chain cyclization, such cyclodimerization (or cyclo-oligomerization) had previously been observed. ${ }^{16,22}$ We obtained the cyclic dimer using the particular resin Fmoc-Asp(Wang resin LL)-ODmab (Novabiochem). 
To minimize dimer formation one could select a resin with lower equivalent of resin loading; however, in the present case, it is a blessing that a cyclic dimer peptide was formed and isolated and found to have more interactions with the antibody, which is a goal sought after.

\section{NMR Results.}

The peptide corresponding to a mass of $628.31 \mathrm{Da}$ (Figure 2B, peak a) was not selected for antibody binding experiments or further 2D NMR experiments because after several trials of synthesis and HPLC re-purifications, while it eluted as a single peak, its ${ }^{1} \mathrm{H}$ 1D NMR spectrum always showed a set of more than four methyl groups present (i.e., eight methyl groups). This suggested a mixture of two enanteomeric peptides, most likely, due to epimerization, which could not be separated by the HPLC column used. The 1D NMR spectrum of the peptide corresponding to a mass of $1255.60 \mathrm{Da}$ (Figure 2B, peak b) showed four set of methyl groups as expected for a dimer cyclic peptide in which one half of the molecule is identical to the other half but in reverse order. Thus, only the peptide corresponding to a mass of $1255.60 \mathrm{Da}$ was selected for further experiments (i.e., antibody binding studies and 2D NMR experiments). Protons assignments were achieved by the 2D NMR TOCSY and ROESY experiments. Table 1 shows the ${ }^{1} \mathrm{H}$ chemical shift assignments for the cyclic dimer peptide.

\begin{tabular}{|c|c|c|c|c|}
\hline \multirow{2}{*}{} & Residue & \multicolumn{3}{|c|}{ Chemical Shifts (ppm) } \\
\cline { 2 - 5 } & $\mathrm{NH}$ & $\alpha \mathrm{H}$ & $\beta \mathrm{H}$ & Others \\
\hline $\mathrm{G}$ & 8.339 & $3.880,4.059$ & & $\gamma \mathrm{CH}_{3} 0.922$ \\
\hline $\mathrm{V}$ & 8.149 & 4.225 & 2.107 & $\gamma \mathrm{CH}_{3} 1.205$ \\
\hline $\mathrm{T}$ & 8.612 & 4.385 & 4.217 & \\
\hline $\mathrm{S}$ & 8.415 & 4.481 & 3.836 & \\
\hline $\mathrm{A}$ & 8.528 & 4.606 & 1.363 & \\
\hline $\mathrm{P}$ & & 4.396 & $2.028,2.316$ & $\mathrm{H} \gamma, \gamma^{\prime} 1.951,2.028 ; \mathrm{H} \delta, \delta^{\prime} 3.664,3.821$ \\
\hline $\mathrm{D}$ & 8.278 & 4.529 & $2.695,2.781$ & \\
\hline
\end{tabular}

Table 1. ${ }^{1} \mathrm{H}$ chemical shifts of cyclic dimer peptide obtained from the TOCSY spectrum. Peptide concentration was $5 \mathrm{mM}$ in $20 \mathrm{mM}$ phosphate buffer, $5 \mathrm{mM} \mathrm{NaCl}, \mathrm{pH} 5,90 \% \mathrm{H}_{2} \mathrm{O}, 10 \% \mathrm{D}_{2} \mathrm{O}$ at $7{ }^{\circ} \mathrm{C}$. Chemical shifts were referenced to the $\mathrm{HDO}$ peak set at $4.970 \mathrm{ppm}$ at $7^{\circ} \mathrm{C}$.

We were able to successfully map out the peptide backbone NOE peaks by the $2 \mathrm{D}{ }^{1} \mathrm{H}$ NMR ROESY data to confirm the correct amino acid sequence. Figure 3 shows the NOE sequential assignments of $\alpha \mathrm{H}_{\mathrm{i}}-\mathrm{NH}_{(\mathrm{i}+1)}$ along the peptide backbone. A unique strong NOE peak bridging the interaction between the GlyNH of chain 1 to the AspHa of chain 2 was observed (Figure 3), attesting the presence of a cyclic peptide. In a linear peptide the NOE 'GlyNH of chain 1 to AspHa of chain 2 ' would not be observed because of the large distance between those two H's and broadening of the NH peak. Additionally, we observed a very weak NOE between the GlyNH and AspNH, further supporting the cyclic structure of the peptide. 


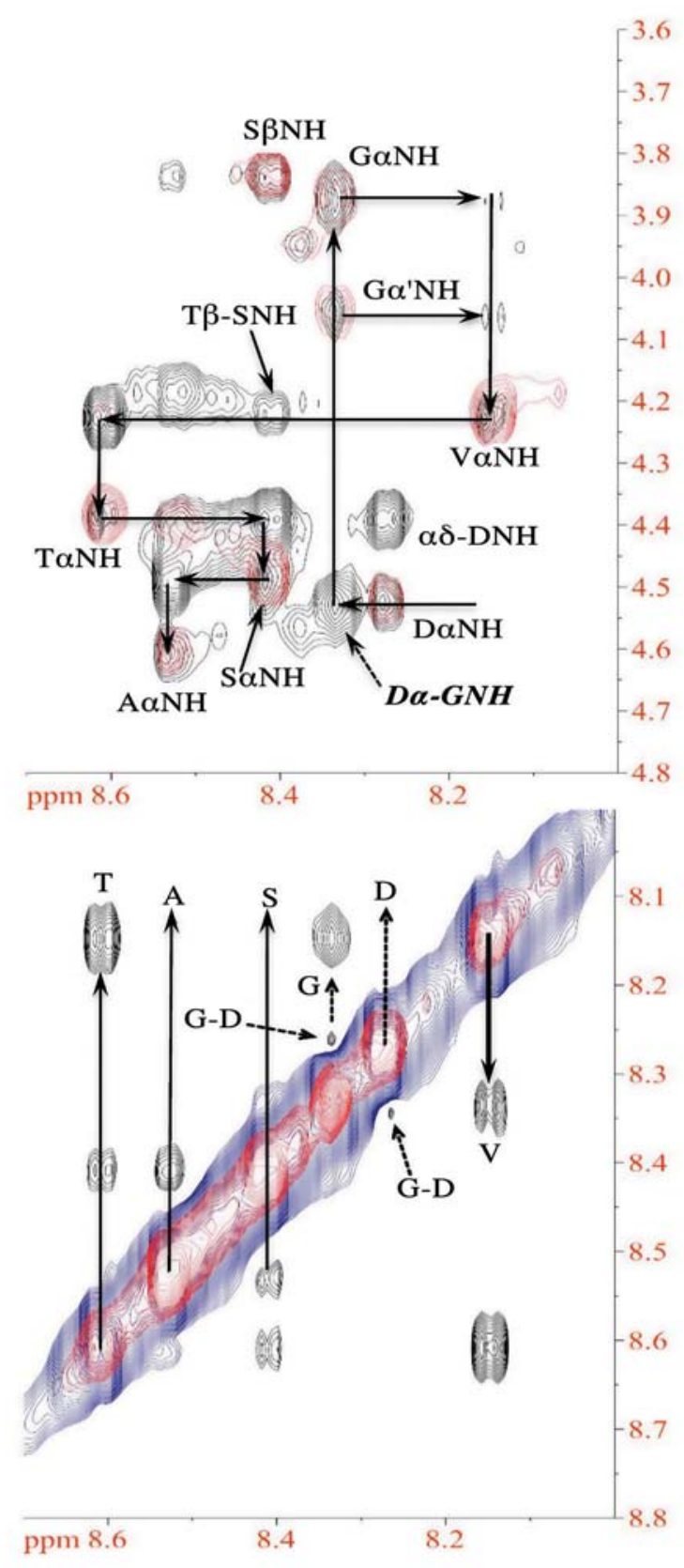

Figure 3. 2D NMR spectra of CHa-NH (top) and NH-NH (bottom) regions of cyclic dimer peptide with sequence cyclo-GVTSAPDGVTSAPD. Black color contours represent ROESY data and red color, TOCSY data. Cross-peaks between Ha's and NH's within each residue are indicated; in addition, a unique NOE peak bridging the interaction between adjacent Asp of chain 2 and Gly of chain 1 (AspHa-GlyNH) confirms the cyclic nature of this molecule (bold label). Arrows show the NOE sequential assignment of the peptide backbone starting with Asp and ending at Ala. Non-label peaks that are not in the backbone connectivity arose from NOE's within the same peptide and from spin systems that we believe were from a minor isomeric peptide. 


\section{STD NMR Results.}

Figure 4 shows the ${ }^{1} \mathrm{H}$ STD NMR results of the cyclic dimer peptide interaction with mouse Muc1 $\mathrm{mAb}(6 \mathrm{~A} 4)$ compare to the linear monomer peptide GVTSAPD previously studied in this laboratory (see reference 13 for ${ }^{1} \mathrm{H}$ assignments and specific details of the linear peptide). ${ }^{12,13}$

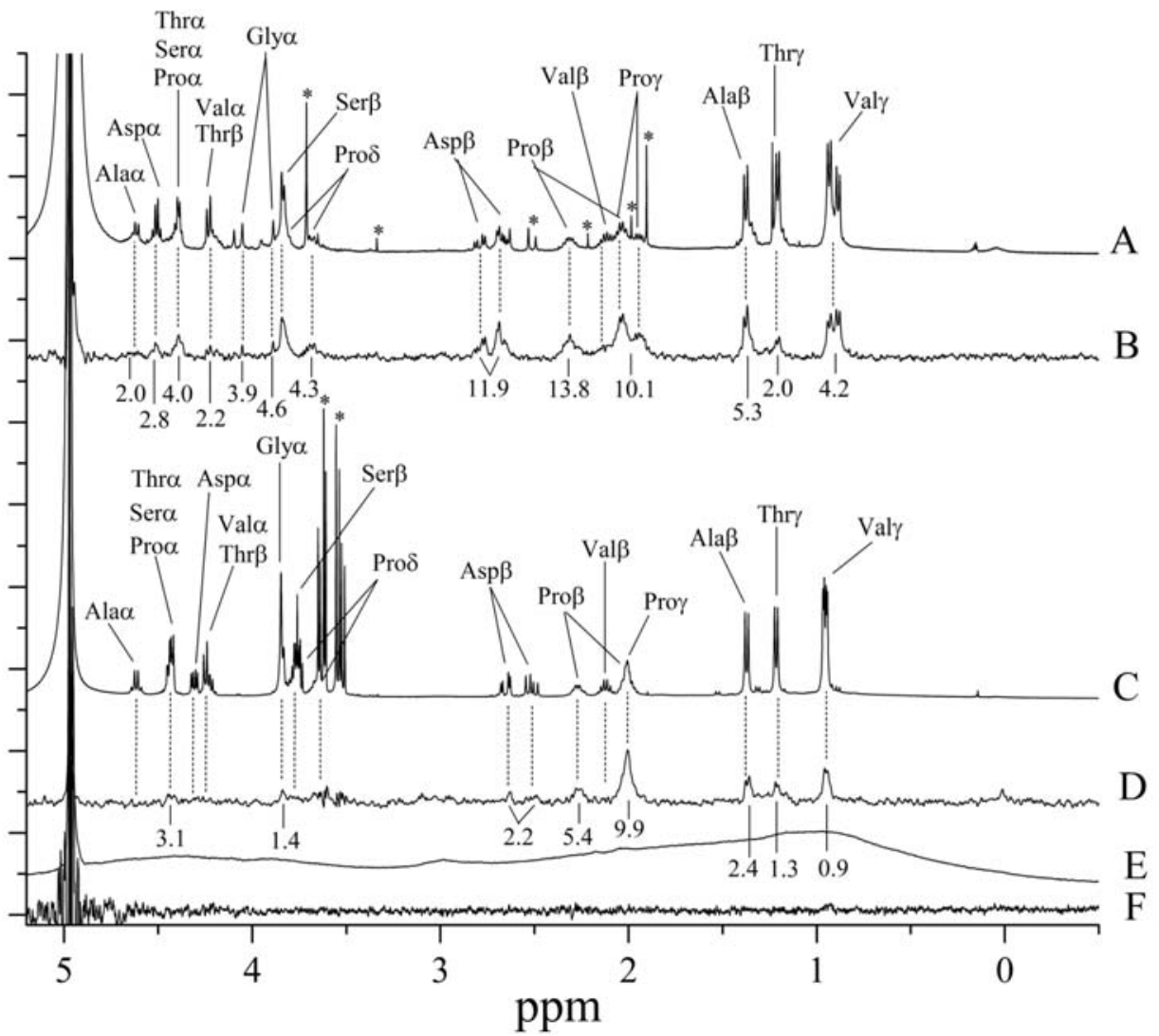

Figure 4. ${ }^{1} \mathrm{H}$ STD NMR spectra of peptides showing protons that give rise to STD peaks as they bind to mAb (6A4). Vertical dashed lines connect the STD peaks to their corresponding protons. A line broadening of $2 \mathrm{~Hz}$ was applied to the STD spectra. The numbers below the STD spectra are ASTD values for the corresponding STD peaks. The traces are: (A) ${ }^{1} \mathrm{H}$ NMR spectrum of a mixture of cyclic dimer peptide (cyclo-GVTSAPDGVTSAPD) and mAb; (B) STD NMR spectrum of cyclic dimer peptide plus mAb; (C) ${ }^{1} \mathrm{H}$ NMR spectrum of a mixture of linear GVTSAPD peptide plus $\mathrm{mAb}$; (D) STD NMR spectrum of linear GVTSAPD peptide plus $\mathrm{mAb}$ (spectra $\mathrm{C}$ and $\mathrm{D}$ are reprinted from reference 13 with the authors' permission); (E) Control STD spectrum of $\mathrm{mAb}$ in the absence of any peptide, only broad humps from the resonances of the $\mathrm{mAb}$ is observed; $(\mathbf{F})$ Control STD spectrum of peptide in the absence of $\mathrm{mAb}$; there are no $\mathrm{mAb}$ peptide interactions, so no STD peaks observed. Peaks marked with “*” are contaminants.

There arose more STD NMR peaks for cyclic dimer peptide than for the monomer linear peptide. In the $\alpha \mathrm{H}-\beta \mathrm{H}$ regions, the results showed clear saturation transfer effects to all the protons of the Pro residue, although the ProHa was overlapped with the aH's of Ser and Thr. Other clear saturation transfer effects occurred at AspHa, $\mathrm{AspH} \beta, \operatorname{SerH} \beta, \mathrm{GlyH \alpha}$, and the methyl groups of Ala, Val and Thr, but the intensity of the Thr methyl group was weaker than those of Ala and Val. The unambiguous peaks corresponding to the protons with the tallest STD NMR signals were from $\mathrm{ValH} \gamma, \mathrm{AlaH} \beta, \mathrm{AspH} \beta, \mathrm{ProH} \beta$ and $\mathrm{ProH} \gamma$ (Figure 4). The Asp residue showed markedly enhanced STD peaks, which was not the case for the linear peptide. The intensities of the various STD peaks for all residues of the cyclic dimer peptide were higher than those of the linear peptide when comparing their amplification factor values. The total ASTD value of Pro and Asp residues were higher than those of other residues. 


\section{DISCUSSION}

The binding of specific monoclonal antibody to the linear sequence GVTSAPD was confirmed in a previous study. ${ }^{12,13}$ It is important to note that Pro6 in that peptide is crucial to the interaction between the peptide antigen and antibody. In this study, through STD NMR, we have determined that the cyclic dimer peptide with the sequence GVTSAPDGVTSAPD has antibody binding ability to Mucl mAb (6A4) with all its residues. Examination of the STD NMR spectrum showed that there are STD peaks corresponding to most of the resonances of the normal ${ }^{1} \mathrm{H}$ NMR spectrum, indicating that most protons of the residues on the cyclic dimer peptide are interacting with the antibody. The STD NMR peak intensity where the resonance of AlaHa is centered is essentially zero. At the methyl group region, the STD NMR peak intensity of ThrH $\gamma$ is weaker than those of Ala and Val. If there are no interactions occurring between the peptide and the antibody the STD spectrum would be a flat line without any peaks, and the higher the STD NMR peak intensity for a particular proton, the closer it is to the antibody. ${ }^{21}$ Inspection of the two STD NMR spectra showed that the STD peaks arose from the cyclic dimer peptide are more pronounced than those from the linear monomer peptide, which suggests the protons of the cyclic dimer peptide are closer to the antibody at the binding interface. The fact that almost all of the protons of all amino acid residues experienced STD effects or are interacting with the antibody suggests that this peptide intercalates its whole self into the binding pocket of the antibody compare to the linear version of the peptide (GVTSAPD), where mainly the Pro residue and the methyl groups have interactions. ${ }^{12,13}$ This may mean that the binding of the cyclic dimer peptide to the antibody is more effective (the dipeptide increases the local concentration of the ligand at the $\mathrm{mAb}$ binding site, which can also lead to an increase in the signal; not necessarily due to increased affinity). This can be expected because the cyclic dimer peptide has the same sequence on both sides of its molecule in reverse order. Base on the higher STD peak intensities of the Pro side chain protons, it appeared that the Pro residue is situated closer to the antibody at the binding pocket than any other residues similar to previous finding for the linear peptide.

It has been previously confirmed from substituted peptides studies that proline is a crucial residue in antibody recognition for this particular sequence. ${ }^{12,13}$ On the cyclic dimer peptide, the $\mathrm{H} \beta$ and $\mathrm{H} \gamma$ on proline displayed highest STD peaks suggesting that they are closer to the antibody binding interface or more accessible to it than the $\alpha \mathrm{H}$ and $\delta \mathrm{H}$ (Figure 4, spectrum B). A conclusion can be drawn from the STD peaks observed for Pro, Val, Ala and Thr that the binding of this peptide to $\mathrm{mAb}$ (6A4) favors a hydrophobic peptide-antibody interface. The side chains of Val and Ala are hydrophobic and contain no heteroatoms, which may explain the similar methyl STD peak intensities (or ASTD values) between the two residues. On the other hand Thr, which contains a hydroxyl group on its $\beta$-carbon, has a side chain of lower hydrophobicity and displayed a lower STD peak intensity. This is consistent with the hypothesis that the antibody molecule prefers to interact with hydrophobic residues on the peptide chain. One striking contrast to this observation is the Asp residue. The side chain of Asp has a low degree of hydrophobicity yet it displayed a much more intense STD peak at the $\mathrm{H} \beta$ compared to the $\mathrm{Thr} \mathrm{CH}_{3}$-group. The Asp side chain wouldn't be supported in a hydrophobic binding site, and therefore is expected to be oriented outside the suggested hydrophobic site. A possible explanation for this is the position of Asp preceded by Pro on the peptide chain, where its sequential location determines its binding property; additionally, a type of secondary structure formed on the cyclic peptide at this region that favors interaction with the antibody is not ruled out. Pro is an important residue in the binding interaction as all of its side chain protons displayed STD peaks. Because of this, Pro would be the residue that is physically nearest in contact with the antibody, and the residues flanking Pro in a cyclic peptide, such as Asp, could be fixed into a constraint that is preferred to interact with the antibody. A more dynamically limited Asp may favor the formation of intermolecular interactions with the antibody. A substitution of Asp for Ala may confirm the above suggested hydrophobic peptide-antibody interface. For the Gly residue, the two geminal protons are not equivalent; both experienced small saturation transfer effect and of about equal STD peak intensity, which suggests Gly is farther away from the binding 
interface. The result is inconclusive whether Ser is involved in the binding, as its $\mathrm{Ha}{ }^{1} \mathrm{H}$ NMR peak overlaps with the Ha's of Thr and Pro, and its $\mathrm{H} \beta$ has overlapping with one of the ProH $\delta$ peaks, contributing further ambiguity to that resonance (at $3.8 \mathrm{ppm}$ ). Because the Pro residue is known to be a binding residue, it is likely, at least, that part of the intensity of the peak appearing at $3.8 \mathrm{ppm}$ also belongs to ProH $\delta$. Additional studies will have to be pursued to determine exactly whether Ser is comprised in the peptide-antibody interface, however, it cannot be excluded because of the peak overlapping described. The fact that the cyclic dimer peptide has more interactions (binds better, not necessarily stronger) with the $\mathrm{mAb}$ compared to the monomer linear peptide is due to two reasons: 1). its residues are constrained in the cyclic peptide, and 2). the doubly repeat sequence in which either side of the peptide is identical in opposite direction allows it to have a higher probability of binding, a kind of double-edge sword property in term of binding to the antibody.

\section{CONCLUSION}

In conclusion, we have synthesized a cyclic dimer mucin peptide with the sequence GVTSAPDGVTSAPD and showed that it possesses Mucl monoclonal antibody binding activity by STD NMR. Almost all of the aliphatic protons of all its amino acid residues gave rise to STD NMR peaks suggesting that most of, if not all, its residues have interactions with the antibody because of its two identical chains of the peptide. Ambiguity does exist in the binding of Ser residue and some of the $\alpha H$ 's due to overlapping resonances. The results clearly showed that the protons of Pro residue and those of the methyl groups of Ala, Thr and Val have interactions with the antibody, signifying the importance of hydrophobic interaction. The data of this study may further suggest the potential usefulness of the cyclic dimer mucin peptide as an additional antigenic valence in immunotherapy of cancer research.

\section{ACKNOWLEDGEMENTS}

This research was supported by Faculty/Student Collaborative grants and Minority Mentoring grants from the University of Wisconsin-Eau Claire (UWEC) Office of Research and Sponsored Program. We thank the UWEC Chemistry Department for its support of many hours of NMR and LC-MS time, and supplies of chemicals.

\section{REFERENCES}

[1] Grinstead, J. S., Koganty, R. R., Krantz, M. J., Longenecker, M. B., and Campbell, P. A. (2002) Effect of Glycosylation on MUC1 Humoral Immune Recognition: NMR Studies of MUC1 Glycopeptide-Antibody Interactions, Biochemistry 41, 9946-9961. doi: 10.1021/bi012176z.

[2] Singh, R., and Bandyopadhyay, D. (2007) MUC1: A Target Molecule for Cancer Therapy, Cancer. Biol. Ther. 6, 481-486. doi: 10.4161/cbt.6.4.4201.

[3] Hollingsworth, M. A., and Swanson, B. J. (2004) Mucins in Cancer: Protection and Control of the Cell Surface, Nature 4, 45-60. doi: 10.1038/nrc1251.

[4] Möller, H., Serttas, N., Paulsen, H., Burchell, J. M., Taylor-Papadimitriou, J., and Meyer, B. (2002) NMR-based determination of the binding epitope and conformational analysis of MUC-1 glycopeptides and peptides bound to the breast cancer-selective monoclonal antibody SM3, Eur. J. Biochem. 269, 1444-1455. doi: 10.1046/j.1432-1033.2002.02787.x.

[5] Kuemmel, A., Single, K., Bittinger, F., Faldum, A., Schmidt, L. H., Sebastian, M., Micke, P., Taube, C., Buhl, R., and Wiewrodt, R. (2009) TA-MUC1 epitope in non-small cell lung cancer, Lung Cancer 63(1), 98-105. doi: 10.1016/j.lungcan.2008.04.005

[6] Gendler, S., Taylor-Papadimitriou, J., Duhig, T., Rothbard, J., and Burchell, J. (1988) A highly immunogenic region of a human polymorphic epithelial mucin expressed by carcinomas is made up of tandem repeats, J. Biol. Chem. 263: 12820-12823. 
[7] Tarp, M. A., Sørensen, A. L., Mandel, U., Paulsen, H., Burchell, J., Taylor-Papadimitriou, J., and Clausen, H. (2007) Identification of a novel cancer-specific immunodominant glycopeptide epitope in the MUC1 tandem repeat, Glycobiology 17(2), 197-209. doi:10.1093/glycob/cwl061.

[8] Vassilaros, S., Tsibanis, A., Tsikkinis, A., Pietersz, G. A., McKenzie, I. F., and Apostolopoulos, V. (2013) Up to 15-year clinical follow-up of a pilot Phase III immunotherapy study in stage II breast cancer patients using oxidized mannan-MUC1, Immunotherapy 5(11), 1177-1182. doi: 10.2217/imt.13.126.

[9] Deguchi, T., Tanemura, M., Miyoshi, E., Nagano, H., Machida, T., Ohmura, Y., Kobayashi, S., Marubashi, S., Eguchi, H., Takeda, Y., Ito, T., Mori, M., Doki, Y., and Sawa, Y. (2010) Increased Immunogenicity of Tumor-Associated Antigen, Mucin 1, Engineered to Express $\alpha$-Gal Epitopes: A Novel Approach to Immunotherapy in Pancreatic Cancer, Cancer Res. 70(13), 5259-5269. doi: 10.1158/0008-5472.CAN09-4313.

[10] Kotera, Y., Fontenot, J. D., Pecher, G., Metzgar, R. S., and Finn, O. J. (1994) Humoral Immunity against a Tandem Repeat Epitope of Human Mucin MUC-1 in Sera from Breast, Pancreatic and Colon Cancer Patients, Cancer Res. 54, 2856-2860.

[11] Kovjazin R., Horn G., Smorodinsky N. I., Shapira M. Y., and Carmon, L. (2014) Cell Surface-Associated Anti-MUC1-Derived Signal Peptide Antibodies: Implications for Cancer Diagnostics and Therapy, PLoS ONE 9(1): e85400. doi: 10.1371/journal.pone.0085400.

[12] Her, C., and Yang, T., (2012) Antibody Binding Study of Mucin Peptide Epitopes. Division of Biological Chemistry, 243rd ACS meeting, San Diego, CA., March 25-29.

[13] Her C., Westler W. M., and Yang T. (2013) Significance of Proline Residue on Short Mucin Peptide Interactions with Mouse MUC1 Monoclonal Antibody Studied by Saturation Transfer Difference NMR Spectroscopy, JSM Chem 1(1): 1004.

[14] Chan, W. C., and White, P. D., (ed.), (2000) Basic Procedures, in Fmoc Solid Phase Peptide Synthesis, A Practical Approach, Oxford University Press, UK, pp. 41-74.

[15] Demmer, O., Frank, A. O., and Kessler, H. (2009) Design of Cyclic Peptides, in Peptide and Protein Design for Biopharmaceutical Applications (ed., K. J. Jensen), John Wiley \& Sons, Ltd, Chichester, UK, pp. 133-166.

[16] Alcaro, M. C., Sabatino, G., Uziel, J., Chelli, M., Ginanneschi, M., Rovero, P., and Papini, A. M. (2004) On-resin Head-to-tail Cyclization of Cyclotetrapeptides: Optimization of Crucial Parameters, J. Peptide Sci. 10, 218-228. doi: 10.1002/psc.512.

[17] Chan, W. C., and White, P. D., (ed.), (2000) RP-HPLC using lipophilic chromatography probes, in Fmoc Solid Phase Peptide Synthesis, A Practical Approach, Oxford University Press, UK, pp. 269-276.

[18] Berger, S., and Braun, S., (ed.), (2004) in 200 and More NMR Experiments, A Practical Course, WILEY-VCH Verlag GmbH \& Co. KGaA, Weinheim, Germany, pp. 422-425.

[19] Piotto, M.., Saudek, V., and SKlenář, V., (1992) Gradient-tailored excitation for single-quantum NMR spectroscopy of aqueous solutions, J. Biomol. NMR 2(6), 661-665. doi: 10.1007/BF02192855.

[20] Mayer, M., and Meyer, B. (2001) Group Epitope Mapping by Saturation Transfer Difference NMR To Identify Segment of a Ligand in Direct Contact with a Protein Receptor, J. Am. Chem. Soc. 123, 6108-6117. doi: 10.1021/ja0100120.

[21] Viegas A., Manso J., Nobrega F. L., and Cabrita E. J. (2011) Saturation-Transfer Difference (STD) NMR: A Simple and Fast Method for Ligand Screening and Characterization of Protein Binding, J. Chem Educ. 88, 990-994. doi: 10.1021/ed101169t.

[22] Sewald, N., and Jakubke, H.-D. (ed.), (2002) Synthesis of Special Peptides and Peptide Conjugates in Peptides: Chemistry and Biology, WILEY-VCH, Verlag GmbH, Weinheim, Germany, pp. 311-337. 


\section{ABOUT THE STUDENT AUTHOR}

Cheng Her graduated with a B.S. degree in Biochemistry/Molecular Biology in 2012 from the University of Wisconsin-Eau Claire. He was a McNair program scholar and had conducted undergraduate research for two years in the Chemistry Dept. He is now attending graduate school in biophysical chemistry at the University of Minnesota-Twin cities, MN.

\section{PRESS SUMMARY}

In this project we intended to synthesize a monomeric cyclic mucin peptide, instead cyclodimerization led to a byproduct that is isolatable from impurities and worth examining for its ability to bind MUC1 mucin monoclonal antibody. The cyclic dimer peptide may be useful to serve as an antigenic epitope for induction of immune response against the mucin antigen.

\section{AJUR volume 12 | Issue 4 | November 2015}

